\title{
Supplementary information to Subsea permafrost and associated methane hydrates: how long will they survive in the future?
}

Valentina V. Malakhova and Alexey V. Eliseev 


\section{S1 SMILES description}

Our model, SMILES (the Sediment Model Invented for Long-tErm Simulations) solves the one-dimensional equation for heat diffusion in the sediments

$$
C \frac{\partial T}{\partial t}=\frac{\partial}{\partial z}\left(\kappa \frac{\partial T}{\partial z}\right)
$$

as well as the diffusion equation for salinity

$$
\frac{\partial(W S)}{\partial t}=\frac{\partial}{\partial z}\left(D_{S} \frac{\partial S}{\partial t}\right) .
$$

Here $C$ is heat capacity per unit volume, $T$ is temperature, $t$ is time, $z$ is vertical coordinate below the sediment top (positive downward), $\kappa$ is thermal conductivity, $W$ is volumetric moisture content of the sediment, $S$ is salinity, and $D_{S}$ is salt diffusivity. We set $C$ and $\kappa$ as it is figured in Table S1. Salt diffusivity in the unfrozen layers is $D_{S}=10^{-9} \mathrm{~m}^{2} \mathrm{~s}^{-1}$, and it is zeroed if layer is frozen.

Boundaries $z=z_{\mathrm{F}}$ between the frozen and unfrozen sediment layers are determined by temperature condition

$$
\left.T\right|_{z_{\mathrm{F}}}=T_{\mathrm{F}},
$$

At these boundaries, the Stefan condition is imposed:

$$
\left.\kappa_{\mathrm{u}} \frac{\partial T}{\partial z}\right|_{\mathrm{u}}-\left.\kappa_{\mathrm{f}} \frac{\partial T}{\partial z}\right|_{\mathrm{f}}=\mathcal{L} W \frac{\partial z_{\mathrm{F}}}{\partial t} .
$$

where $\mathcal{L}$ is latent heat of fusion, and $W$ is volumetric moisture content of the sediment, subscripts ' $u$ ' and 'f' depict values of the thermal properties corresponding to unfrozen and frozen layers correspondingly. Volumetric latent heat of fusion is set equal to the value corresponding to the distilled water, $3.34 \times 10^{8} \mathrm{~J} \mathrm{~m}^{-3}$.

Heat and salt diffusion equations are coupled via $T_{\mathrm{F}}$ dependence on $S$ and pressure $P$ (Galushkin et al., 2012):

$$
T_{\mathrm{F}}=-\alpha_{P} P-\alpha_{S} S
$$

\begin{tabular}{|c|c|c|c|c|}
\hline \multirow{2}{*}{$z, \mathrm{~m}$} & \multicolumn{2}{|c|}{$C, \mathrm{MJ} \mathrm{m}^{-3} \mathrm{~K}^{-1}$} & \multicolumn{2}{|c|}{$\kappa, \mathrm{W} \mathrm{m}^{-1} \mathrm{~K}^{-1}$} \\
\hline & unfrozen & frozen & unfrozen & frozen \\
\hline $0-200$ & 2.63 & 2.01 & 1.38 & 2.30 \\
\hline $200-800$ & 2.70 & 2.34 & 1.75 & 2.70 \\
\hline $800-1500$ & 2.15 & 2.10 & 2.30 & 2.75 \\
\hline
\end{tabular}

Table S1: Thermophysical properties of the sediments: heat capacity $C$ and heat diffusivity $\kappa$ as prescribed in the sediments. 
with $\alpha_{P}=7.3 \times 10^{-2} \mathrm{MPa}^{-1}$ and $\alpha_{S}=6.4 \times 10^{-2} \mathrm{psu}^{-1}$ (psu is practical salinity unit).

The boundary conditions for Eqs. (S1) and (S2) at the top of the sediments are

$$
\left.T\right|_{z=0}=T_{\mathrm{B}}
$$

and

$$
\left.S\right|_{z=0}=S_{\mathrm{B}} .
$$

The respective boundary conditions at the bottom of the computational domain in the sediments

$$
\left.\kappa \frac{\partial T}{\partial z}\right|_{z=H_{\mathrm{S}}}=G
$$

and

$$
\left.S\right|_{z=H_{\mathrm{S}}}=0 .
$$

Here $H_{\mathrm{S}}$ is thickness of the computational domain in the sediment column. We set $H_{\mathrm{S}}=1,500 \mathrm{~m}$.

We assume that sediment pores are filled with water up to their holding capacity. Sediment porosity exponentially decreases downward from the value 0.4 at the top of the sediments with the vertical scale 2,500 m (Sclater and Christie, 1980).

Model equations are solved by using the sweep method at a discrete vertical grid with a vertical step of $0.5 \mathrm{~m}$. Time stepping scheme is implicit with the a time step of 1 mo. We do not resolve annual cycle.

The equilibrium pressure-temperature curve for methane hydrates is adopted from the TOUGH ${ }^{+}$HYDRATE model as it is reported in the inlet to Fig. 1 of (Reagan and Moridis, 2008):

$$
\ln \left(P_{\mathrm{h}}\right)=\sum_{n=0}^{5} a_{n} T_{\star}^{n},
$$

with $a_{n}$ as figured in Table S2. Here $T_{\star}$ is temperature corrected to the saltinduced depression

$$
T_{\star}=T-\Delta T_{\mathrm{D}}
$$

with

$$
\Delta T_{\mathrm{D}}=\Delta T_{\mathrm{D}, \mathrm{ref}} \frac{\ln \left(1-x_{\mathrm{s}}\right)}{\ln \left(1-x_{\mathrm{s}, \mathrm{ref}}\right)} .
$$

Here $x_{\mathrm{s}}$ is molar fraction of salt in the pore water, $\Delta T_{\mathrm{D} \text {,ref }}=2 \mathrm{~K}, x_{\mathrm{s}, \text { ref }}=0.0134$ (Reagan et al., 2011).

\section{S2 Initial conditions}

Initial temperature distribution is prescribed as

$$
T\left(z_{j}, t=0\right)=T\left(z_{j-1}, t=0\right)+G\left(z_{j}-z_{j-1}\right) / \kappa_{j} .
$$


Table S2: Coefficients $a_{n}$ in Eq. (S10). Temperature $T_{\star}$ is in kelvins and the equilibrium pressure $P_{\mathrm{h}}$ is in megapascals.

\begin{tabular}{ccc}
\hline$n$ & $T_{\star}>273.2 \mathrm{~K}$ & $T_{\star}<273.2 \mathrm{~K}$ \\
\hline 0 & -1.94138504464560 & -4.38921173434628 \\
1 & 3.31018213397926 & 7.76302133739303 \\
2 & -2.25540264493806 & -7.27291427030502 \\
3 & +7.67559117787059 & 3.85413985900724 \\
4 & -1.30465829788791 & -1.03669656828834 \\
5 & 8.86065316687571 & 1.09882180475307 \\
\hline
\end{tabular}

Here subscript $j$ indicates computational level within the sediment (numbered from top to bottom), $\kappa_{j}$ is thermal conductivity at this level, and $T\left(z_{0}, t=0\right)=$ $T_{\mathrm{B}}(t=0)$. The resulting $T(z, t=0)$ is almost linear with respect to $z$. Such profile would be in equilibrium with the specified boundary conditions provided that heat diffusivity is independent from the vertical coordinate. However, because heat diffusivity changes in the vertical direction between frozen and unfrozen layers, we need to spin up the model for $3 \mathrm{kyr}$.

Initial condition for salt diffusion equation is prescribed as a final state from the previous run (Malakhova and Eliseev, 2020) to avoid strong salinity drift. Namely, the glaciation cycle for 400-340 kyr B.P. (before present) is repeated several times, and $S$ drift is visually inspected in the whole computational column. It appeared that 7 repetitions of this cycle is enough to achieve the salinity drift throughout the whole computational domain. Then, the final output of this spin up was used for the non-glacial conditions 400 kyr B.P.

\section{S3 Boundary conditions}

At the sediment-ocean interface (or at the sediment-air interface if the sediments are in contact with the air during oceanic regressions), temperature and salinity are prescribed to time-dependent functions $T_{\mathrm{B}}$ and $S_{\mathrm{B}}$. In particular, when shelf is in contact with the atmosphere, $T_{\mathrm{B}}$ is set equal to air temperature $T_{\mathrm{a}}$, and $S_{\mathrm{B}}$ is zeroed. When shelf is covered by water, $T_{\mathrm{B}}\left(S_{\mathrm{B}}\right)$ is prescribed to be equal to the near-bottom water temperature (salinity) $T_{\mathrm{w}}\left(S_{\mathrm{w}}\right)$. Both $T_{\mathrm{w}}$ and $S_{\mathrm{w}}$ are functions of the present-day shelf depth $H_{\mathrm{D}}$ (Fig. S3). In addition to this at the time of the post-glacial oceanic transgression, we calculate the fraction of time when water layer thickness is smaller than $z_{\star}=0.5 \mathrm{~m}$. This fraction is computed as $\left(z_{\star} / 10 \mathrm{~m}\right) \times t_{10}$, and $t_{10}$ is the time interval to rise the sea level from $-10 \mathrm{~m}$ to zero. For this time interval, it is assumed that $T_{\mathrm{w}}=-0.5^{\circ} \mathrm{C}$ and $S_{\mathrm{w}}=25 \mathrm{psu}$. At the bottom of sediment domain (1,500 $\mathrm{m}$ in our model), time-independent heat flux $G$ from the Earth interior and no-flux condition for salinity are adapted.

Time-dependent $T_{\mathrm{a}}$ is constructed from the monthly mean SAT as simulated 
Table S3: $T_{\mathrm{w}}$ and $S_{\mathrm{w}}$ as functions of the present-day shelf depth $H_{\mathrm{D}}$.

\begin{tabular}{ccc}
\hline$H_{\mathrm{D}}, \mathrm{m}$ & $T_{\mathrm{w}},{ }^{\circ} \mathrm{C}$ & $S_{\mathrm{w}}, \mathrm{psu}$ \\
\hline 10 & -1.3 & 27 \\
50 & -1.7 & 34 \\
100 & -1.9 & 34 \\
\hline
\end{tabular}

with the CLIMBER-2 for time interval from $400 \mathrm{kyr}$ B.P. to the time instant $t=0$, which corresponds to the common era (C.E.) year 1950 (Ganopolski et al., 2016).

From the CLIMBER-2 output, a grid cell, which covers the East Siberian Arctic shelf (ESAS), is extracted. Note that because of very coarse horizontal resolution of CLIMBER-2 ( $10^{\circ}$ in latitude and $51.4^{\circ}$ in longitude Petoukhov et al., 2000), a single grid cell covers the entire EEAS (the area from $77.1^{\circ} \mathrm{E}$ to $128.6^{\circ} \mathrm{E}$ and from $70^{\circ} \mathrm{N}$ to $80^{\circ} \mathrm{N}$ ). CLIMBER-2 output is available as anomalies from the above-defined present-day state. Thus, $T_{\mathrm{a}}$ is constructed by adding the present-day temperature in this area $\left(-12^{\circ} \mathrm{C}\right.$, Nicolsky et al., 2012) to the CLIMBER-2 output (Fig S1).

Then, our simulations are continued for $100 \mathrm{kyr}$ ('future'; $t>0$ ). For future, we assume that the shelf is always covered by the water, but SAT changes. Thus, for future $T_{\mathrm{B}}=T_{\mathrm{w}}+\Delta T_{\text {fut }}$. In the first series of simulations, $T_{\text {fut }}$ is set equal to $T_{\mathrm{a}}(t)-T_{\mathrm{a}}(0)$. For this, we use the continuation of the CLIMER-2 simulations forced by changes of parameters of the Earth orbit and by anthropogenic $\mathrm{CO}_{2}$ emissions into the atmosphere (Ganopolski et al., 2016). These emissions start in nominal year 1950 and proceed with the same, simulation- and time-independent rate until the prechosen cumulative emission level $E_{\text {tot }}$ is achieved. Upon this, anthropogenic $\mathrm{CO}_{2}$ emission rate is set to zero, and the CLIMBER-2 simulation is continued with a freely evolving carbon cycle.

The SMILES simulation employing $T_{\mathrm{B}}$, which is based on the CLIMBER-2 simulation with $E_{\text {tot }}=1000 \mathrm{PgC}$, is denoted as TR1000. In a similar fashion, we use the CLIMBER-2 output for the simulation with $E_{\text {tot }}=3000 \mathrm{PgC}$ to construct the forcing for our simulation further denoted TR3000. In turn, our simulation TR0 is forced by $T_{\mathrm{B}}$, which is a repetition of the CLIMBER-simulated SAT for year 1950 C.E. copied for the whole future period (thus, $T_{\text {fut }} \equiv 0$ in TR0).

The CLIMBER-simulated SAT anomalies in the above-mentioned grid cell differ from the zonal mean SAT change at the same latitude no more than by $20 \%$ for the entire TR3000 simulation. For the TR1000 simulation, the respective difference is within 10\% except for the period 55-60 kyr in future and for the last $10 \mathrm{kyr}$ of the simulation (Fig. S2).

We neglect the impact of future sea level rise on hydrostatic pressure.

Depending on simulation, $G$ is set equal to either $45 \mathrm{~mW} \mathrm{~m}^{-2}$ or to $60 \mathrm{~mW} \mathrm{~m}^{-2}$ or to $75 \mathrm{~mW} \mathrm{~m}^{-2}$. 

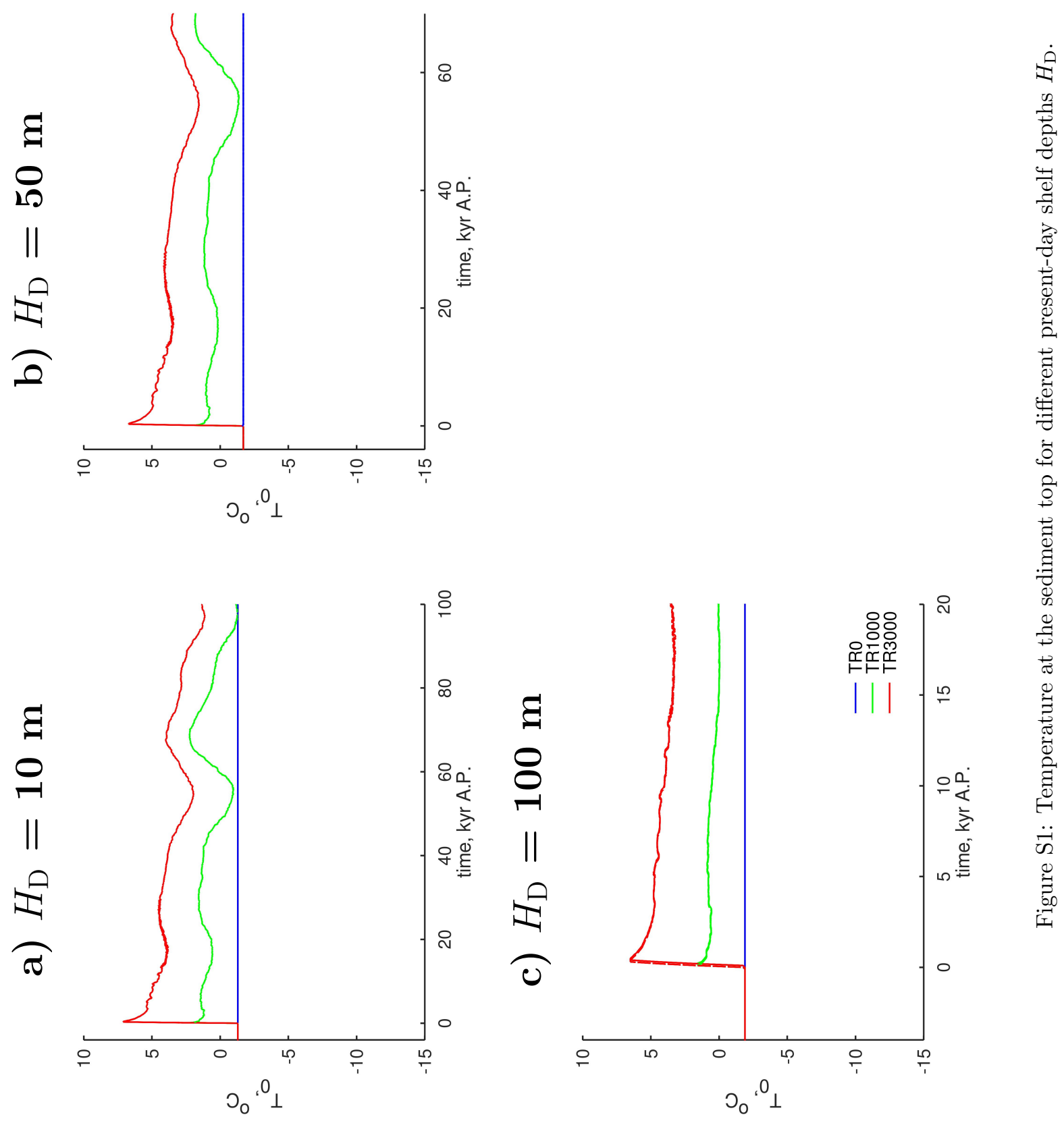


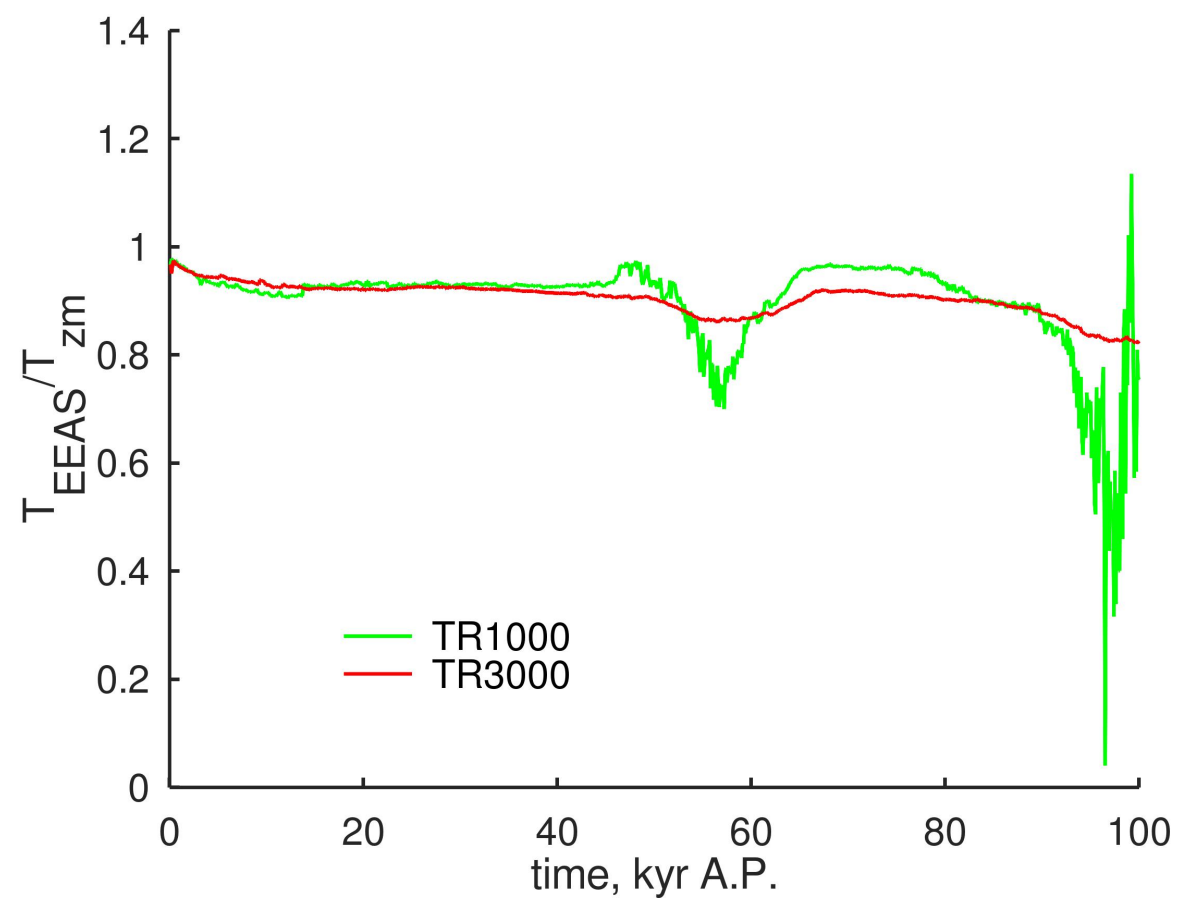

Figure S2: Ratio of the CLIMBER-simulated surface air temperature anomalies in the selected grid cell to zonal mean at the same latitude 


\section{S4 Shelf regions}

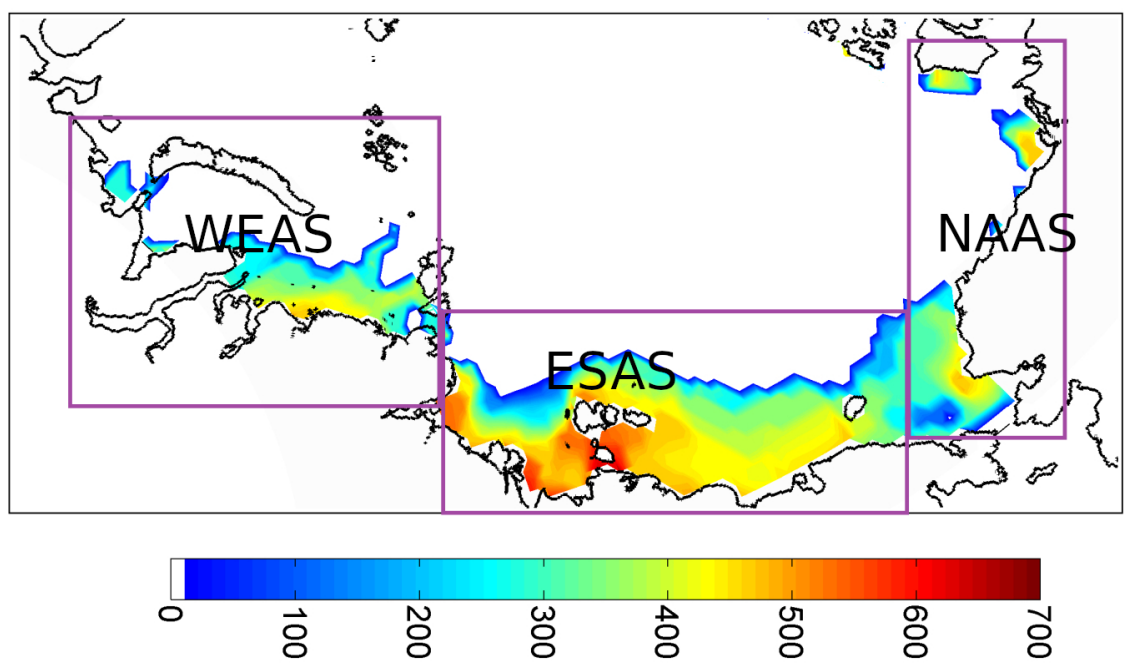

Figure S3: Depth of the subsea permafrost bottom (meters) in 1948 (modified after (Malakhova, 2020)). Rectangles show shelf regions adapted in the present paper: WEAS (West Eurasian Arctic Shelf), ESAS (East Siberian Arctic Shelf), NAAS (North American Arctic Shelf).

Table S4: Permafrost area $\left(10^{5} \mathrm{~km}^{2}\right)$ as simulated by (Malakhova, 2020) at the parts of the contemporary Arctic shelf depicted in Fig. S3 as a function of the present day shelf depth $H_{\mathrm{D}}$.

\begin{tabular}{cccc}
\hline$H_{\mathrm{D}}, \mathrm{m}$ & WEAS & ESAS & NAAS \\
\hline$\leq 30$ & 1.19 & 3.16 & 1.07 \\
from 30 to 75 & 8.89 & 4.61 & 0.74 \\
$>75$ & 0 & 3.50 & 0.23 \\
\hline
\end{tabular}




\section{S5 Supplement for pan-Arctic estimates}

a) $F_{\mathrm{CH}_{4}, \mathrm{w}}, \mathrm{ESAS}$

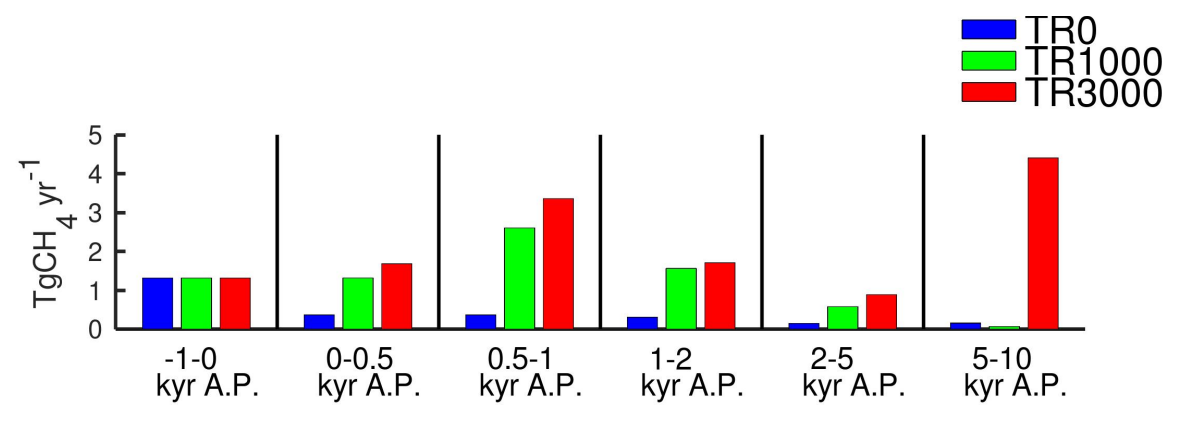

b) $F_{\mathrm{CH}_{4}, \mathrm{w}}$, WEAS

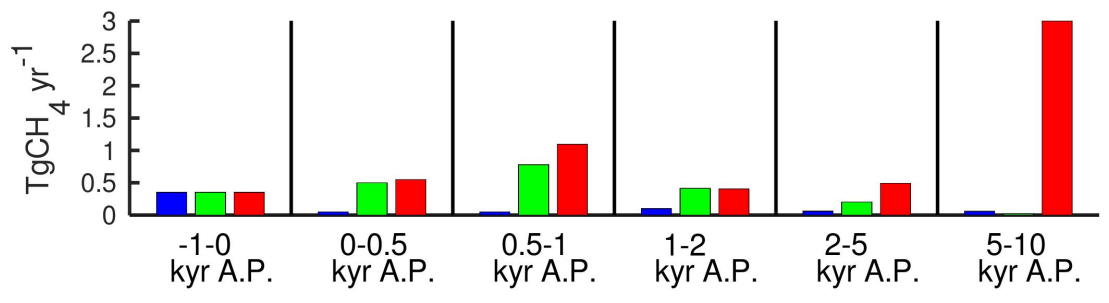

c) $F_{\mathrm{CH}_{4}, \mathrm{w}}, \mathrm{NAAS}$

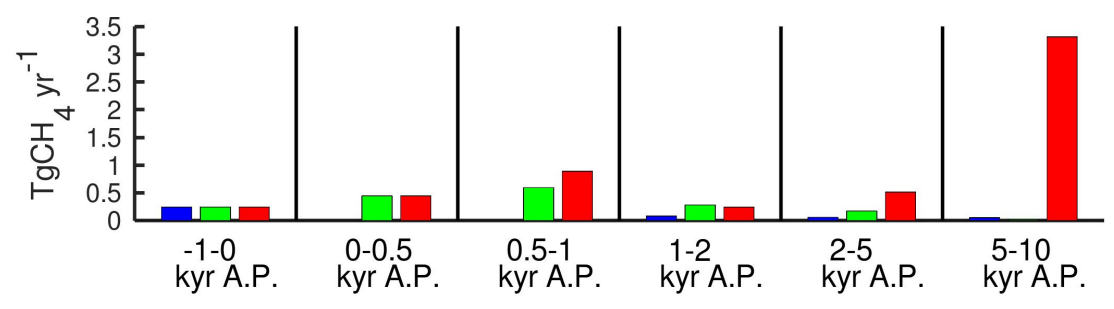

Figure S4: Similar to fig. 7b of the main text but with a breakdown into shelf regions. 


\section{References}

Galushkin, Y., K.A., S., and Frolov, S.: Permafrost formation and degradation in the Urengoy and Kuyumbinskaya areas of Siberia. Part 2. Influence of variations in thermophysical parameters of frozen rocks on temperature and heat flow distributions with depth, Earth Cryosphere, XVI, 23-29, 2012.

Ganopolski, A., Winkelmann, R., and Schellnhuber, H.: Critical insolation- $\mathrm{CO}_{2}$ relation for diagnosing past and future glacial inception, Nature, 529, 200203, https://doi.org/10.1038/nature16494, 2016.

Malakhova, V.: The response of the Arctic Ocean gas hydrate associated with subsea permafrost to natural and anthropogenic climate changes, IOP Conf. Ser.: Earth and Environ.l Sci., 606, 012 035, https://doi.org/10.1088/17551315/606/1/012035, 2020.

Malakhova, V. and Eliseev, A.: Salt diffusion effect on the submarine permafrost state and distribution as well as on the stability zone of methane hydrates on the Laptev Sea shelf, Ice and Snow, 60, 533-546, https://doi.org/ 10.31857/S2076673420040058, [in Russian], 2020.

Nicolsky, D., Romanovsky, V., Romanovskii, N., Kholodov, A., Shakhova, N., and Semiletov, I.: Modeling sub-sea permafrost in the East Siberian Arctic Shelf: The Laptev Sea region, J. Geophys. Res.: Earth Surface, 117, F03 028, https://doi.org/10.1029/2012JF002358, 2012.

Petoukhov, V., Ganopolski, A., Brovkin, V., Claussen, M., Eliseev, A., Kubatzki, K., and Rahmstorf, S.: CLIMBER-2: A climate system model of intermediate complexity. Part I: model description and performance for present climate, Clim. Dyn., 16, 1-17, https://doi.org/10.1007/PL00007919, 2000.

Reagan, M. and Moridis, G.: Dynamic response of oceanic hydrate deposits to ocean temperature change, J. Geophys. Res.: Oceans, 113, C12023, https://doi.org/10.1029/2008JC004938, 2008.

Reagan, M., Moridis, G., Elliott, S., and Maltrud, M.: Contribution of oceanic gas hydrate dissociation to the formation of Arctic Ocean methane plumes, J. Geophys. Res.: Oceans, 116, C09 014, https://doi.org/ 10.1029/2011JC007189, 2011.

Sclater, J. and Christie, P.: Continental stretching: An explanation of the PostMid-Cretaceous subsidence of the central North Sea Basin, J. Geophys. Res.: Solid Earth, 85, 3711-3739, https://doi.org/10.1029/JB085iB07p03711, 1980. 